\title{
FLEXIBILIDADE NA HABITAÇÃO SOCIAL: A PRÁTICA E A TEORIA EM BUSCA DA QUALIDADE ESPACIAL
}

UBERLÂNDIA 2019

\author{
LOGSDON, Louise \\ Instituto Federal de Mato Grosso, e-mail: lovise.logsdon@cba.ifmt.edu.br \\ PEREIRA, Lucas $M$. \\ Universidade de São Paulo, e-mail: Ic.melchiori@gmail.com \\ FRANCO, Júlio \\ Universidade de São Paulo, e-mail: julio.frc@gmail.com \\ FABRICIO, Márcio $M$. \\ Universidade de São Paulo, e-mail: marcio@sc.usp.br
}

\begin{abstract}
RESUMO
Esta pesquisa é fruto de um trabalho desenvolvido em uma disciplina de pós-graduação (mestrado/doutorado) ocorrida no segundo semestre de 2018, no Instituto de Arquitetura e Urbanismo da Universidade de São Paulo. A disciplina discutiu aspectos de qualidade espacial e requisitos do usuário, propondo como exercício a elaboração de projetos de moradias sociais em plataforma BIM (Building Information Modeling). Neste contexto, o objetivo deste artigo é apresentar uma proposta de projeto de habitação social flexível, desenvolvida na disciplina a partir da análise crítica de um projeto do Programa Minha Casa Minha Vida (PMCMV). Para isso, a pesquisa partiu de uma revisão bibliográfica sobre qualidade espacial e flexibilidade na habitação, passou pela análise do citado projeto do PMCMV, até concluir-se com a proposta da nova solução projetual, mais flexível e mais compatível às necessidades dos usuários. $\mathrm{O}$ projeto demonstra que, com alguns cuidados e com um certo aumento de área construída, é possível aumentar consideravelmente a qualidade espacial da moradia. Nesse sentido, o trabalho contribui com as discussões sobre a prática de projeto de habitação social, fornecendo subsídios à comunidade acadêmica e aos projetistas interessados.
\end{abstract}

Palavras-chave: projeto de habitação; qualidade habitacional; funcionalidade.

\begin{abstract}
This research is the result of a postgraduate course (master's / doctorate) held in the second half of 2018, at the Institute of Architecture and Urbanism of the University of São Paulo. The course discussed aspects of spatial quality and user requirements, proposing the elaboration of a social housing design, in BIM (Building Information Modeling) platform. In this context, the objective of this paper is to present a proposal for a flexible social housing design, developed in the course, after a critical analysis of a design of "Programa Minha Casa Minha Vida". The research started with a bibliographical revision on spatial quality and flexibility in housing, passed thought an analysis of the aforementioned PMCMV design, until concluding with the proposal of the new design solution, more flexible and more compatible with the needs of users. The design demonstrates that, with some care and with a certain increase of built area, it is possible to considerably increase the spatial quality of the dwelling. So, this paper contributes to the discussions of social housing design, providing subsidies both to academia and design community.
\end{abstract}

Keywords: housing design; housing quality; functionality.

LOGSDON, L.; PEREIRA, L. M.; FRANCO, J.; FABRICIO, M. M. Flexibilidade na habitação social: a prática e a teoria em busca da qualidade espacial. In: SIMPÓSIO BRASILEIRO DE QUALIDADE DO PROJETO NO AMBIENTE CONSTRUÍDO, 6., 2019, Uberlândia. Anais... Uberlândia: PPGAU/FAUeD/UFU, 2019. p. 1550-1560. DOI https://doi.org/10.14393/sbqp19139. 


\section{INTRODUÇÃO}

O histórico de baixa qualidade construtiva, ambiental e arquitetônica das moradias sociais brasileiras tem sido constatado por diversos pesquisadores (ORNSTEIN; ROMERO, 2003; REIS; LAY, 2002; VILLA; CARVALHO, 2012; VILLA; GARCIA, 2011). Apesar da satisfação com a posse da casa, os beneficiários se deparam com ambientes muito pequenos, insuficientes para o mobiliário e para a circulação. Aspectos mínimos de habitabilidade, funcionalidade e privacidade não são atendidos e, em consequência, moradores se veem condicionados a realizar mudanças na edificação. Essas alterações - reformas e ampliações - geralmente não são previstas em projeto e prejudicam a circulação, a privacidade e as condições de conforto das unidades (BRASIL, 2014; SZÜCS et al., 2007; VILLA; SARAMAGO; SILVA, 2015).

O conceito de qualidade refere-se à adequação das características de qualquer produto às necessidades e expectativas dos seus usuários, sendo verificáveis por meio da análise de conformidade com as especificações de qualidade cabíveis (FABRICIO; ORNSTEIN; MELHADO, 2010; PAIVA, 2002). No caso do projeto de habitação de interesse social (HIS), o cliente - aquele que contrata o projeto - não será responsável pela operação, uso e manutenção da edificação e geralmente não está preocupado com os atributos de usabilidade desse projeto. É compromisso do projetista, no entanto, prestar seus serviços àquele que será o maior beneficiado da qualidade deste produto: o morador, usuário final da moradia (PALERMO, 2013).

Para atender às necessidades de usuários que, a princípio, são desconhecidos, a literatura recomenda a atenção à princípios norteadores, como a funcionalidade e a flexibilidade. A funcionalidade leva em consideração o atendimento às atividades desempenhadas na moradia, sua relação com o espaço e os equipamentos/móveis necessários (AMORIM et al., 2015; PALERMO, 2009; PEDRO, 2001). A flexibilidade apresenta-se como solução potencial para que um projeto possa se adaptar com facilidade às diferentes necessidades e desejos dos seus ocupantes, seja antes da ocupação ou durante o tempo de permanência ou uso. É uma forma de atender composições familiares diversas, atendendo também às novas demandas que podem surgir com mudanças na composição familiar que podem ocorrer ao longo do tempo de uso daquela moradia (BRANDÃO, 2011; SCHNEIDER; TILL, 2007).

\subsection{Objetivo da pesquisa e delineamento do método}

Este trabalho aponta reflexões sobre as possibilidades de ampliação da qualidade da produção do PMCMV, com foco no atendimento às necessidades espaciais dos usuários. Mais especificamente, o objetivo do artigo é discutir um caso de elaboração de projeto de HIS flexível, que leva em consideração as diferentes composições familiares e as possíveis alterações em suas demandas e necessidades, em termos de espaços na moradia.

Para isso, a pesquisa seguiu quatro etapas principais: (1) revisão bibliográfica quando foram levantados os requisitos de projeto que conferem qualidade espacial, funcionalidade e flexibilidade à moradia; (2) caso de referência quando um projeto do PMCMV foi analisado qualitativamente, segundo os requisitos encontrados na etapa anterior; (3) proposta de projeto - quando se desenvolveu o projeto de uma moradia flexível, levando em consideração a 
correção dos aspectos negativos encontrados no projeto de referência; (4)análise comparativa - comparação entre as relações de custo e os atributos de qualidades identificados no caso de referência e na proposta de projeto, empregando para tanto um instrumento de verificação dos níveis de funcionalidade e flexibilidade de HIS (LOGSDON, 2019).

\section{FUNCIONALIDADE E FLEXIBILIDADE NO PROJETO DA HABITAÇÃO}

O conceito de funcionalidade é tratado por diversos autores como um princípio que confere qualidade ao projeto da moradia, capaz de oferecer ao usuário final o espaço e as condições necessárias para o desempenho das atividades domésticas. Sua investigação parte da compreensão da satisfação de necessidades humanas, no sentido de viabilizar essas atividades em espaços apropriados e com os equipamentos necessários. Dessa forma, três critérios norteiam o projeto de moradias funcionais: o programa habitacional; as áreas e dimensões dos espaços da moradia; o mobiliário mínimo e sua área de uso (AMORIM et al., 2015; PALERMO, 2009; PEDRO, 2001; PEREIRA, 2015).

O programa habitacional, entendido aqui como o programa de necessidades da habitação, refere-se prioritariamente à relação das funções e atividades desenvolvidas na moradia aos espações e ambientes que a compõem (MOREIRA; KOWALTOWSKI, 2011; PEDRO, 2001). As diversas atividades domésticas envolvem um conjunto de funções, elencada por diversos autores em: (1) dormir / descansar; (2) preparo de refeições; (3) alimentar-se; (4) estar / receber / conviver; (5) lazer / recreio; (6) estudo / trabalho; (7) lidar com a roupa; (8) higiene pessoal; (9) manutenção / arrumação (10) permanecer no exterior; (11) armazenar; (12) circular (AMORIM et al., 2015; ABNT, 2013; PALERMO, 2009; PEDRO, 2001; SILVA, 1982). Essas funções distribuem-se nos ambientes da moradia - sala, cozinha, banheiro, serviços, dormitórios, varanda - que não precisam ser necessariamente compartimentados. Reconhecidamente, ambientes como sala e cozinha podem estar integrados e atividades domésticas podem ocorrer em mais de um local, simultaneamente ou alternativamente: atividades de estudo e trabalho, por exemplo, podem acontecer na sala, no dormitório e/ou em um cômodo específico.

Com relação às áreas e dimensões mínimas, estudos anteriores recomendam relações entre área e número de habitantes, por exemplo, onde considera-se satisfatório o intervalo entre 11 e $14 \mathrm{~m}^{2}$ /habitantes (ORNSTEIN; ROMERO, 2003; PALERMO, 2009; SILVA, 1982). Algumas normas, como a NBR 15.575 (ABNT, 2013) e os códigos de obras municipais, elencam dimensões mínimas de determinados compartimentos - pé-direito mínimo, largura mínima da cozinha e do banheiro, por exemplo. Mais importante que atender estes números, no entanto, é garantir que o projeto da unidade habitacional tenha espaço suficiente para atender às diversas atividades domésticas, incluindo o conjunto de móveis/equipamentos necessários para seu desempenho, bem como as condições adequadas de acesso, uso e circulação.

Frente a isso, a literatura elenca o conjunto mínimo do mobiliário da habitação, especificando suas dimensões e áreas de uso. A NBR 15.575 traz a exigência mínima, mas vários autores fazem uma análise crítica do que seria este mínimo necessário, oferecendo maiores subsídios (IMAI, 2010; PALERMO, 2009; PEDRO, 2011; PEREIRA, 2015). Logsdon e Fabrício (2019) apresentam 
material aprofundado sobre o assunto e disponibilizam para download famílias BIM do mobiliário popular, com suas áreas de uso e demais.

O segundo atributo de qualidade espacial destacado aqui, flexibilidade, remete à capacidade de adaptação da moradia, incluindo o potencial de realizar mudanças e adequações antes da sua ocupação e também durante o tempo de permanência ou uso. É uma condição da forma arquitetônica, que resulta da aplicação de estratégias projetuais, tanto pela organização espacial quanto pelos processos e sistemas construtivos (ABREU; HEITOR, 2007; BRANDÃO, 2011 ; FINKELSTEIN, 2009; PAIVA, 2002; SCHNEIDER; TILL, 2007).

Dentro do conceito de flexibilidade, no entanto, incluem-se algumas formas de aplicação que se relacionam às estratégias arquitetônicas adotadas. A flexibilidade oferecida ao futuro morador antes do momento de ocupação, seja pela escolha/customização da planta ou pela possibilidade de personalização durante a obra, é chamada de flexibilidade inicial. E a flexibilidade que possibilita ao morador realizar adequações na unidade ao longo do tempo de uso é chamada de flexibilidade contínua. Esta última pode ser obtida também por diferentes estratégias: pelo uso múltiplo de espaços - através da neutralidade dos compartimentos; da alteração entre a relação dos espaços por períodos limitados; ou pela sobreposição das funções nos ambientes - e pela alteração das características físicas da habitação, seja dentro do perímetro da construção, ou ampliando este perímetro.

Diversos autores classificam os tipos ou formas de aplicação da flexibilidade e, após uma análise comparativa, pôde-se notar a similaridade e a equiparidade das estratégias (Quadro 1). Apenas dois itens não são correspondentes entre si: não há correspondência nos demais autores à estratégia de multifuncionalidade, elencada por Abreu e Heitor (ABREU; HEITOR, 2007), nem à junção e desmembramento, listada por Brandão (2002). O Quadro 2 elenca, portanto, as definições dos tipos de flexibilidade, indicando estratégias ou meios para alcançá-las. Como a multifuncionalidade se refere à alteração da função da edificação - residencial para comercial, por exemplo - ela foi suprimida neste trabalho. 
Quadro 1 - Classificação dos tipos de flexibilidade

\begin{tabular}{|c|c|c|c|c|c|c|c|}
\hline & $\begin{array}{l}\text { Coelho } \\
\text { (1993) }\end{array}$ & $\begin{array}{c}\text { Galfertti } \\
\text { (1997) }\end{array}$ & $\begin{array}{l}\text { Pedro } \\
(2001)\end{array}$ & $\begin{array}{l}\text { Paiva } \\
(2002)\end{array}$ & $\begin{array}{c}\text { Brandão } \\
\text { (2002) }\end{array}$ & $\begin{array}{c}\text { Abreu e } \\
\text { Heitor } \\
\text { (2007) }\end{array}$ & $\begin{array}{c}\text { Finkels- } \\
\text { tein } \\
(2009)\end{array}$ \\
\hline \multirow{3}{*}{$\begin{array}{l}\overline{\bar{O}} \\
\frac{\underline{U}}{\underline{E}} \\
\dot{x} \\
\frac{1}{4}\end{array}$} & $\begin{array}{l}\text { Flexibilidade } \\
\text { de comparti- } \\
\text { mentação }\end{array}$ & - & $\begin{array}{l}\text { Separação } \\
\text { estrutura / } \\
\text { partição }\end{array}$ & $\begin{array}{l}\text { Estratégias de } \\
\text { projeto }\end{array}$ & \multirow[b]{2}{*}{$\begin{array}{l}\text { Flexibilidade } \\
\text { propriamente } \\
\text { dita }\end{array}$} & \multirow[b]{2}{*}{ Conversão } & \multirow[b]{2}{*}{ B3* } \\
\hline & 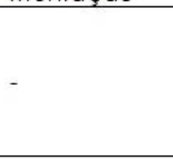 & & $\begin{array}{l}\text { Participação } \\
\text { do usuário } \\
\text { (no projeto, } \\
\text { gestão ou } \\
\text { construção) }\end{array}$ & $\begin{array}{l}\text { Participação } \\
\text { do usuário } \\
\text { (no processo } \\
\text { ou na } \\
\text { construção) }\end{array}$ & & & \\
\hline & - & & - & $\begin{array}{l}\text { Oferta } \\
\text { diversificada }\end{array}$ & $\begin{array}{l}\text { Diversidade } \\
\text { tipológica }\end{array}$ & Diversidade & $\mathrm{A} 2^{*}$ \\
\hline \multirow{6}{*}{ 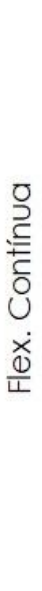 } & Mobilidade & Mobilidade & \multirow{2}{*}{$\begin{array}{l}\text { Uso múltiplo } \\
\text { dos espaços }\end{array}$} & Neutralidade & \multirow{2}{*}{$\begin{array}{l}\text { Adaptabili- } \\
\text { dade }\end{array}$} & \multirow{2}{*}{ Polivalência } & \multirow{2}{*}{$\begin{array}{l}\mathrm{A} 1^{*} \\
\mathrm{~B} 1^{*} \\
\mathrm{~B} 2^{*} \\
\mathrm{~B}^{*}\end{array}$} \\
\hline & $\begin{array}{l}\text { de encerra- } \\
\text { mento }\end{array}$ & & & Mutalidade & & & \\
\hline & $\begin{array}{l}\text { Evolução } \\
\text { simples }\end{array}$ & Evolução & \multirow{2}{*}{$\begin{array}{l}\text { Alteração } \\
\text { das caracte- } \\
\text { rísticas físicas } \\
\text { Dentro do } \\
\text { perímetro } \\
\text {..................... } \\
\text { Modificando } \\
\text { o limite da } \\
\text { habitação }\end{array}$} & \multirow{2}{*}{$\begin{array}{l}\text { Alteração } \\
\text { das caracte- } \\
\text { rísticas físicas } \\
\text { Dentro do } \\
\text { perímetro } \\
\text {...................... } \\
\text { Modificando } \\
\text { o limite da } \\
\text { habitação }\end{array}$} & \multirow{2}{*}{$\begin{array}{l}\text { Ampliabili- } \\
\text { dade } \\
\text { Sem } \\
\text { aumento de } \\
\text { área } \\
\text { com................. } \\
\text { aumento de } \\
\text { área }\end{array}$} & \multirow[b]{2}{*}{ Expansão } & \multirow[b]{2}{*}{ B 4* } \\
\hline & Elasticidade & Elasticidade & & & & & \\
\hline & - & - & & - & $\begin{array}{l}\text { Junção e } \\
\text { desmembra- } \\
\text { mento }\end{array}$ & - & - \\
\hline & - & - & & - & - & $\begin{array}{l}\text { Multifuncio- } \\
\text { nalidade }\end{array}$ & - \\
\hline
\end{tabular}

*A1 = espaços neutros; $\mathrm{A} 2$ = alternativas de plantas; $\mathrm{B} 1$ = possibilidades de layout; $\mathrm{B} 2$ = mudanças ao longo do dia; B3 = projetos inacabados; B4 = projetos expansíveis; B5 = possibilidade de subdividir ou integrar espaços Fonte: Os autores.

\section{Quadro 2 - Definição dos tipos de flexibilidade}

\begin{tabular}{|c|c|c|}
\hline Tipo de Flexibilidade & \multicolumn{2}{|l|}{ Definição } \\
\hline $\begin{array}{l}\text { Flexibilidade de } \\
\text { compartimentação, } \\
\text { flexibilidade propriamente dita } \\
\text { ou conversão }\end{array}$ & \multicolumn{2}{|c|}{$\begin{array}{l}\text { Liberdade de reformular a organização do espaço interno, dentro de um perímetro } \\
\text { rigidamente definido, geralmente com intervenção construtiva (BRAND ÃO, 2002). } \\
\text { Possibilidade de variar formas de uso, através de alteração na configuração espacial } \\
\text { da moradia (ABREU; HEIOR, 2007). }\end{array}$} \\
\hline $\begin{array}{l}\text { Diversidade, diversidade } \\
\text { tipológica ou oferta } \\
\text { diversificada }\end{array}$ & \multicolumn{2}{|c|}{$\begin{array}{l}\text { Refere-se à preconcepção de um empreendimento com várias plantas diferentes, } \\
\text { princip almente no que diz respeito a áreas privativas e número de quartos, ou seja, } \\
\text { com diversidade de unidades-tipo em um mesmo edifício ou conjunto habitacional } \\
\text { (BRANDÃO, 2002). }\end{array}$} \\
\hline $\begin{array}{l}\text { Adaptabilidade, suas } \\
\text { equivalências e subdivisões- } \\
\text { mobilidade, polivalência, } \\
\text { mutabilidade, neutralidade }\end{array}$ & \multicolumn{2}{|c|}{$\begin{array}{l}\text { Possibilidade funções simultâneas ou da troca de funções de um único ambiente, por } \\
\text { meio de divisórias móveis ou pela própria disposição do mobiliário, sem intervenção } \\
\text { construtiva. As mudanças devem ser feitas pelo próprio usuário, de maneira fácile } \\
\text { rápida, podendo se dar ao longo do dia ou de periodos sazonais (BRANDÃO, 2002; } \\
\text { PAIVA, 2002). }\end{array}$} \\
\hline \multirow[t]{2}{*}{$\begin{array}{l}\text { Ampliabilidade, evolução ou } \\
\text { elasticidade }\end{array}$} & \multicolumn{2}{|c|}{$\begin{array}{l}\text { Possibilidade da unidade habitacional re ceber a adição de novos ambientes ou } \\
\text { cômodos. }\end{array}$} \\
\hline & $\begin{array}{l}\text { Ampliabilidade externa (add-on): } \\
\text { adição de peças, aumentando o limite } \\
\text { ou o perímetro da edificação } \\
\text { (BRANDÃO, 2006). }\end{array}$ & $\begin{array}{l}\text { Ampliabilidade interna (add-in): } \\
\text { aproveitamento de espaço interno pré- } \\
\text { existente - sótão, porão ou terraço- } \\
\text { ampliando a área útil da edificação, sem } \\
\text { alterar seu perímetro (BRANDÃO, 2006). }\end{array}$ \\
\hline Junção e desmembramento & \multicolumn{2}{|c|}{$\begin{array}{l}\text { É o caso em que há união de unidades em uma maior, e também o contrário, } \\
\text { quando uma unidade é desmembrada em mais unidades. Uma unidade absorve a } \\
\text { outra por completo: de dois apartamentos, faz-se um e vice-versa (BRANDÃO, 2002). }\end{array}$} \\
\hline
\end{tabular}

Fonte: Os autores.

Estas formas de aplicação da flexibilidade podem ser encontradas em conjunto ou individualmente. Um projeto pode ter caráter evolutivo - que visa a ampliação futura - e não oferecer possibilidades de adaptações internas, 
por exemplo. Certamente, quanto mais estratégias adotadas, mais flexível é o projeto. No entanto, as intenções do projetista podem ser ponderadas e justificadas em função do atendimento às necessidades do público-alvo e demais condicionantes.

O conteúdo apresentado nesta seção serviu para fundamentar as próximas etapas da pesquisa: a análise de projetos e a elaboração de uma proposta de moradia que incorporasse os conceitos e as estratégias demonstradas aqui.

\section{PROJETO DE REFERÊNCIA}

O projeto analisado foi a unidade do Nilce Paes Barreto, lançado pelo PMCMV Faixa 1 na cidade de Cuiabá-MT. É um projeto notadamente rígido, com uma configuração mínima e áreas muito reduzidas que dificultam o mobiliamento adequado.

A Figura 1 apresenta a planta na UH utilizada como referência, onde são destacadas algumas observações negativas relacionadas à funcionalidade. No primeiro dormitório, falta espaço para berço ou móvel complementar (1), não há circulação adequada nas duas laterais da cama (2) e caso seja alocado um roupeiro do tamanho indicado pela NBR 15.575, a porta não terá varredura completa (3). No segundo dormitório, falta uma mesa de estudos (4) e a área de uso e circulação das camas é menor que a recomendada (5). No banheiro, o espaço previsto para uso da bacia, lavatório e box são inferiores ao recomendado (6). A área de serviço, que consiste na instalação do tanque sob o beiral, não tem espaço para uso dos equipamentos (7). Na cozinha, falta espaço para mesa de apoio e armário extra (8). Na sala, falta um aparador/estante (9), e a área de uso da mesa é bem aquém da recomendada (10). Ou seja, em todos os compartimentos faltam itens do mobiliário básico e a área de uso/circulação é menor que o recomendado.

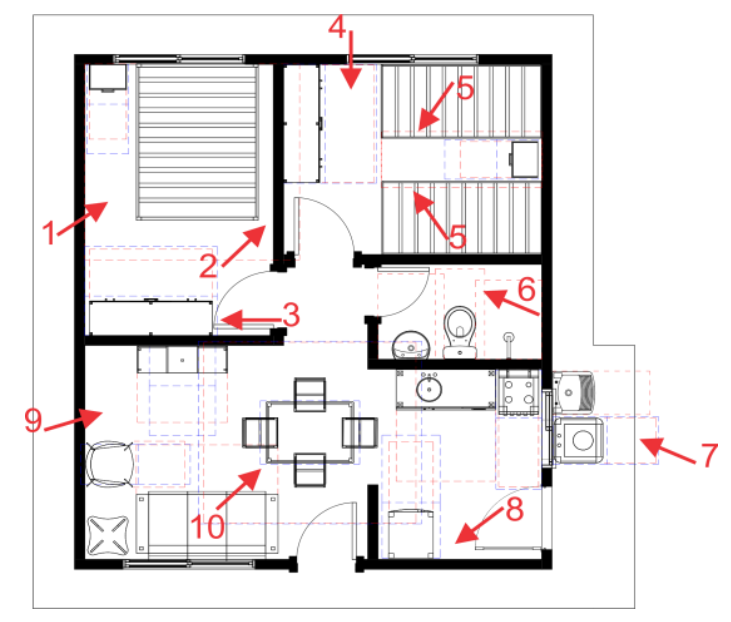

Figura 1 - Planta baixa do projeto analisado

Fonte: Os autores (2018)

Com relação à flexibilidade, o projeto é ainda menos favorável. Existe apenas 1 tipo de planta, com 2 dormitórios, independente da composição familiar que receberá a moradia. Quanto às ampliações futuras, a expansão da casa torna-se mais viável apenas para o sentido lateral, visto que a cobertura tem cumeeira paralela à frente do lote. No entanto, não há projeto para futuras ampliações nem indicação do sentido de expansão da UH. Além disso, a casa é construída em alvenaria e não são previstos meios reversíveis de alterar as 
relações entre os compartimentos; não há nenhum cômodo multiuso e não foram propostas outras disposições de layout.

Trata-se, portanto, de um projeto com vários pontos negativos, tendo em vista a sua qualidade espacial. Esses fatores deverão ser excluídos ou mitigados na nova solução proposta.

\section{PROPOSTA DE MORADIA FLEXÍVEL}

A proposição de projeto flexível apresenta quatro tipos de UHs (Figura 2). A estratégia para o desenvolvimento do projeto parte da elaboração de um modelo de plataforma de 1 dormitório, 1 banheiro, lavanderia, cozinha e uma sala com varanda. A partir desta unidade são previstas composições alternativas, com as opções de 2 dormitórios, 3 dormitórios e 3 dormitórios com suíte. Essas opções atendem à grande maioria das composições familiares. Além disso, em razão da modularidade dos cômodos em cada versão, as unidades com menos dormitórios podem ser facilmente ampliadas para comportar novas instalações.

O sistema construtivo adotado neste projeto é misto, empregando alvenaria estrutural nas paredes externas, associada à vedação interna com paredes de steel frame entre os dormitórios e uma estrutura independente para 0 travamento da parede que separa a área social da área íntima e da cobertura, o que possibilita a movimentação ou retirada das paredes de steel frame caso haja interesse, sem interferência estrutural. Além disso, são previstos painéis removíveis para alterar a posição da porta de acesso nas posições indicadas na planta.

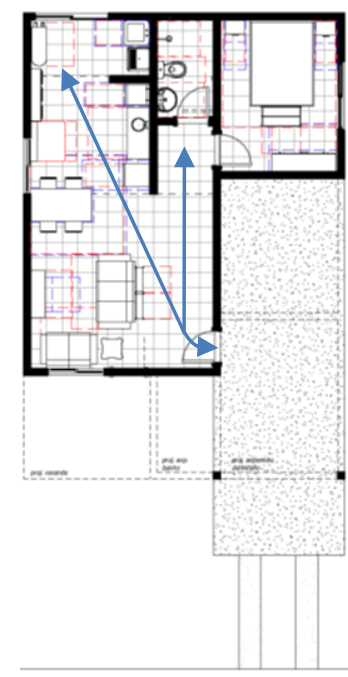

(a)

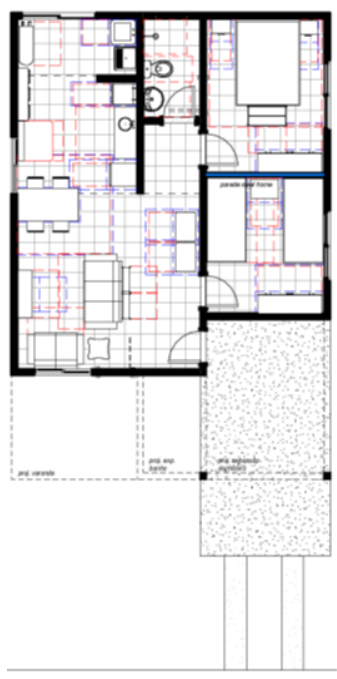

(b)

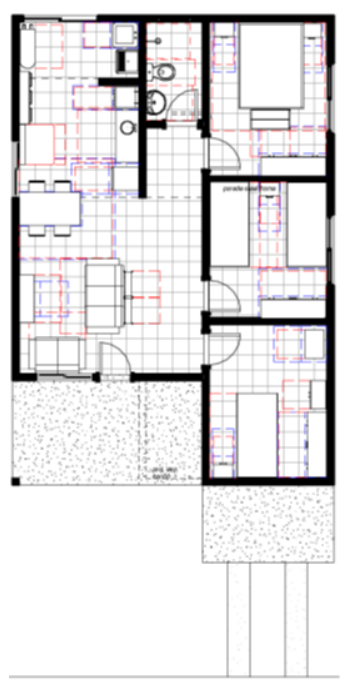

(c)

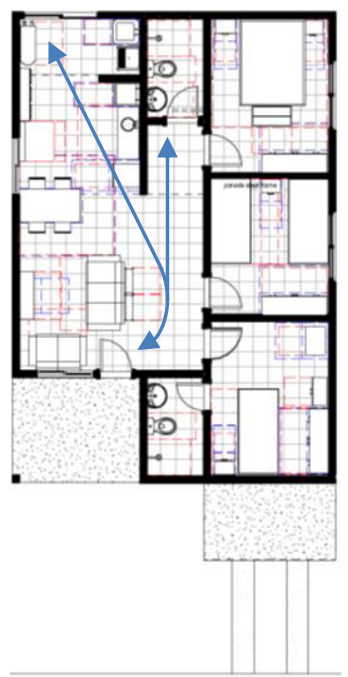

(d)

Figura 2 - Planta das unidades de 1 (a), 2 (b) e 3 (c e d) dormitórios Fonte: Os autores (2018)

Os layouts propostos obedecem às orientações de funcionalidade para os cômodos, tais como faixa de circulação livre que considera não apenas o mobiliário básico, mas também a sugestão de mobiliário complementar. Por exemplo, o espaço para berço no quarto do casal, a mesa de estudos na sala, o armário e a mesa de apoio na cozinha, a tábua de passar na área de serviço, etc. Em termos gerais, a área de uso de todos os itens do mobiliário são compatíveis com o que é determinado pela NBR 15.575 (ABNT, 2013). 

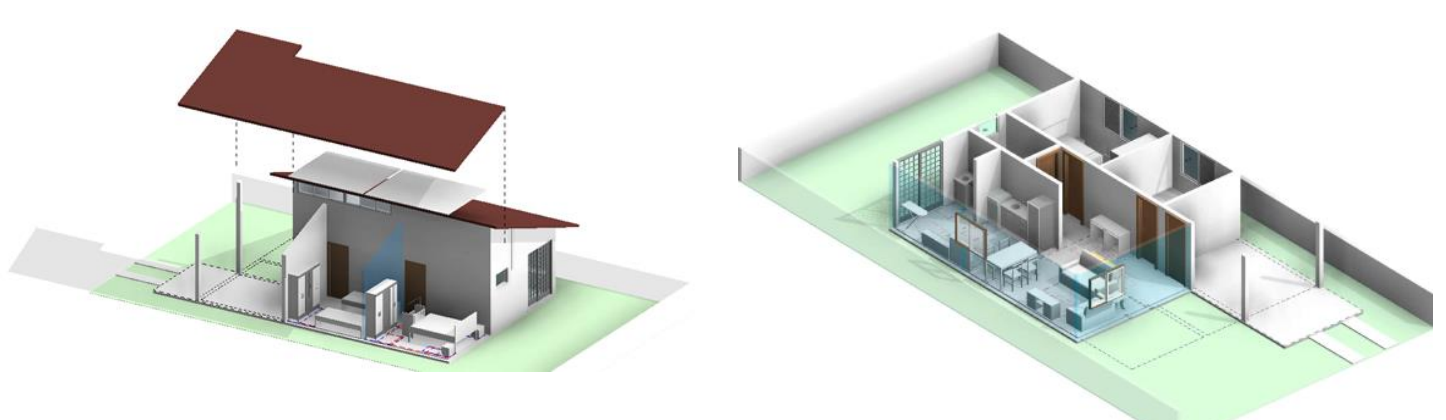

Figura 3 - Perspectivas da unidade de 2 dormitórios

Fonte: Os autores (2018)

\section{ANÁLISE COMPARATIVA}

A análise comparativa entre o projeto de referência e as opções propostas foi possível graças à aplicação de um instrumento de verificação dos níveis de funcionalidade e flexibilidade de HIS que se encontra em estágio avançado de desenvolvimento (LOGSDON, 2019). Tanto os requisitos de funcionalidade quanto os de flexibilidade foram mais verificados nas soluções propostas do que no projeto original do PMCMV.

Diferente do projeto de referência, onde a área de serviço se resume a um tanque sob o beiral, a área de serviço da proposta é um ambiente interno, ventilado, por onde ocorre o acesso à área externa. Outra característica distintiva é que a proposta apresenta um eixo de circulação livre, enquanto o caso de referência apresenta uma circulação tortuosa, obstruído pela mesa.

Todavia, sob uma perspectiva financeira, a proposta de 2 dormitórios, cujo programa equivale à apresentada pela referência, indicada no Quadro 3 como "planta original", apresenta um de acréscimo de área de 55\%, que em uma estimativa unitária impactaria sobre os custos totais.

\section{Quadro 3 - Relação de custo x níveis de funcionalidade e flexibilidade das UHs}

\begin{tabular}{lccccrr} 
Descrição & $\begin{array}{c}\text { Flexibilidade } \\
\text { (base=1; max=2) }\end{array}$ & $\begin{array}{c}\text { Funcionalidade } \\
\text { (máx=1) }\end{array}$ & $\begin{array}{c}\text { índice de qualidade } \\
\text { (máx=3) }\end{array}$ & Área & Custo total & $\begin{array}{r}\text { Acréscimo ao } \\
\text { original (\%) }\end{array}$ \\
\hline Planta original & 0,96 & 0,76 & 1,72 & $36,90 \mathrm{~m}^{2}$ & $\mathrm{R} \$ 50.920,89$ & - \\
\hline Proposta 1 dorm. & 1,96 & 1,00 & 2,96 & $48,24 \mathrm{~m}^{2}$ & $\mathrm{R} \$ 66.569,75$ & $30,73 \%$ \\
\hline Proposta 1 dorm. + garagem & 1,96 & 1,00 & 2,96 & $57,60 \mathrm{~m}^{2}$ & $\mathrm{R} \$ \mathbf{7 9 . 4 8 6 , 2 7}$ & $56,10 \%$ \\
\hline Proposta 2 dorm. & $\mathbf{2 , 0 0}$ & $\mathbf{1 , 0 0}$ & $\mathbf{3 , 0 0}$ & $\mathbf{5 7 , 4 0 \mathrm { m } ^ { 2 }}$ & $\mathbf{R} \$ \mathbf{7 9 . 2 1 0 , 2 8}$ & $\mathbf{5 5 , 5 6 \%}$ \\
\hline Proposta 2 dorm. + garagem & 2,00 & 1,00 & 3,00 & $64,34 \mathrm{~m}^{2}$ & $\mathrm{R} \$ \mathbf{8 8 . 7 8 7 , 2 7}$ & $74,36 \%$ \\
\hline Proposta 3 dorm. & 2,00 & 1,00 & 3,00 & $68,10 \mathrm{~m}^{2}$ & $\mathrm{R} \$ \mathbf{9 3 . 9 7 5 , 9 6}$ & $84,55 \%$ \\
\hline Proposta 2 dorm. + 1 suíte & 2,00 & 1,00 & 3,00 & $71,45 \mathrm{~m}^{2}$ & $\mathrm{R} \$ \mathbf{9 8 . 5 9 8 , 8 6}$ & $93,63 \%$ \\
\hline
\end{tabular}

* Custo Unitário Básico Da Construção Civil (CUB) de Janeiro de 2018 Fonte: Os autores (2018)

A comparação evidencia uma relação conflituosa entre o estabelecimento de custos permissivos insuficientes e o atendimento aos requisitos dos moradores, que resulta em um quadro de baixa qualidade relacionada a funcionalidade e flexibilidade. Ao tornar evidente tais variáveis, é possível recuperar a discussão acerca da qualidade de HIS iniciada na teoria, com impacto sobre as decisões de projeto e, extrapolando, provocar a necessidade por uma redefinição das diretrizes de programas como MCMV, de forma a considerar os custos reais para construção de habitações que respondam às expectativas e necessidades de seus moradores. 


\section{CONSIDERAÇÕES FINAIS}

O trabalho indica que, se levadas em consideração as diretrizes de funcionalidade e flexibilidade encontradas na literatura, o projeto da habitação social pode apresentar um melhor desempenho em relação às demandas espaciais atuais e futuras de seus moradores.

A verificação dos níveis de flexibilidade e funcionalidade em uma HIS permitem direcionar os empreendimentos para atendimento das condições de qualidade de projeto a partir de soluções alcançadas principalmente por meio de resoluções de planta. Como o custo está relacionado principalmente à definição de recursos construtivos, mais do que ao aumento de área, entende-se que é mais efetivo buscar economias em elementos verticais. Assim, a evolução dos custos apresentados são apenas estimativas referenciais, a serem abordadas adequadamente no projeto. Isso significa que a relação de custo benefício deve partir de condições de qualidade associadas à disposição e áreas adequadas para os ambientes, aceitando o aumento de custos iniciais, e explorar estratégias de adequação ao custo permissivo por meio de negociação de detalhamentos construtivos com parceiros e fornecedores da cadeia de suprimentos.

O reconhecimento da necessidade de uma abordagem complementar fortalece a relevância do instrumento de verificação dos níveis de flexibilidade e funcionalidade, ao definir uma relação de prioridade alinhada a evolução iterativa do projeto. Esta orientação se alinha a trabalhos de custeio-meta e valor-meta, que apontam a solução de redução de custos por meio de negociação das condições de redução de custos de operação da construção sem precarização do espaço construído.

Disciplinas orientadas a prática como esta apresentam resultados práticos e teóricos ricos para o desenvolvimento profissional e reflexão de pesquisa. A disciplina da pós-graduação reuniu a prática de projeto à discussão teórica, tendo sido bem produtiva e enriquecedora. Relatos de disciplinas que estimulam a aplicação deste e outros conhecimentos, como projeto orientado ao TVD, demonstram o mérito deste modelo de aplicação.

Cabe ainda uma reflexão sobre a perspectiva de integrar as análises de funcionalidade e flexibilidade e análise de criação de valor do projeto. $O$ instrumento em desenvolvimento, que apoia essa verificação pode ser associado a instrumentos de TVD, de forma a promover um processo que subsidie o balanceamento de custos e benefícios durante a concepção do projeto.

\section{AGRADECIMENTOS}

Os autores agradecem à disposição dos professores e discentes envolvidos na disciplina, bem como ao programa de pós-graduação do Instituto de Arquitetura e Urbanismo da Universidade de São Paulo (IAU-USP) que a ofertou. Agradecem ainda ao Instituto Federal de Educação, Ciência e Tecnologia de Mato Grosso (IFMT) e à FAPESP, pelo apoio ao desenvolvimento da pesquisa, processo $n^{\circ}$ 2015/06367-9. 


\section{REFERÊNCIAS}

ABREU, R.; HEITOR, T. Estratégias de Flexibilidade na arquitetura doméstica holandesa: da conversão à multifuncionalidade. 2007. Disponível em: <http://infohabitar.blogspot.com/2007/01/estratgias-de-flexibilidade-na.html> Acesso em junho de 2019.

AMORIM, C. N. D. et al. Qualidade do projeto arquitetônico. In: BLUMENSCHEIN, R. N.; PEIXOTO, E. R.; GUINANCIO, C. (Org). Avaliação da qualidade da habitação de interesse social: projetos urbanístico e arquitetônico e qualidade construtiva. Brasília: UnB, FAU, 2015. p. 102-139.

ASSOCIAÇÃO BRASILEIRA DE NORMAS TÉCNICAS (ABNT). NBR 15.575-1. Edifícios habitacionais - Desempenho. Parte 1: Requisitos Gerais. Rio de Janeiro: ABNT, 2013.

BRANDÃO, D. Q. Diversidade e potencial de flexibilidade de arranjos espaciais de apartamentos: uma análise do produto imobiliário no Brasil. Tese (Doutorado em Engenharia de Produção), Universidade Federal de Santa Catarina, Florianópolis, 2002.

BRANDÃO, D. Q. Habitação Social evolutiva: aspectos construtivos, diretrizes para projetos e proposição de arranjos espaciais flexíveis. Cuiabá: CEFET-MT, 2006.

BRANDÃO, D. Q. Disposições técnicas e diretrizes para projeto de habitações sociais evolutivas. Ambiente Construído (Online), v. 11, n. 2, p. 73-96, 2011.

BRASIL. Pesquisa de satisfação dos beneficiários do Programa Minha Casa Minha Vida. Brasília: MCidades; SNH; SAE-PR; IPEA, 2014.

FABRICIO, M. M.; ORNSTEIN, S. W.; MELHADO, S. B. Conceitos de qualidade no projeto de edifícios. In: FABRICIO, M. M.; ORNSTEIN, S. W. (Org). Qualidade no projeto de edifícios. São Carlos: RiMa Editora, ANTAC, 2010. p. 5-22.

FINKELSTEIN, C. W. Flexibilidade na Arquitetura Residencial - um estudo sobre o conceito e sua aplicação. Dissertação (Mestrado pelo Programa de Pesquisa e Pós-graduação em Arquitetura), Universidade Federal do Rio Grande do Sul, Porto Alegre, 2009.

IMAI, C. O sonho da moradia no projeto: o uso da maquete arquitetônica na simulação da habitação social. Maringá: EdUEM, 2010.

LOGSDON, L. Qualidade Habitacional: Instrumental de apoio ao projeto de moradias sociais. [s.I.] Tese (Doutorado pelo Instituto de Arquitetura e Urbanismo), Universidade de São Paulo, São Carlos, 2019.

LOGSDON, L.; FABRICIO, M. M. Funcionalidade e Mobiliário da Habitação: Contribuições para o Projeto de Moradias Sociais. Arquitetura Revista, v. 15, n. 2, 2019.

MOREIRA, D. C.; KOWALTOWSKI, D. C. C. K. O programa arquitetônico. In: KOWALTOWSKI, D. C. C. K. et al. (Org). O processo de projeto em arquitetura. São Paulo: Oficina de Textos, 201 1. p. 101-108.

ORNSTEIN, S. W.; ROMERO, M. A. Avaliação Pós-Ocupação: Métodos e Técnicas aplicados à Habitação Social. Porto Alegre: ANTAC, 2003. 
PAIVA, A. L. S. A. Habitação flexível - Análises de conceitos e soluções.

Dissertação (Mestrado em Arquitetura da Habitação): Faculdade de Arquitectura da Universidade Técnica de Lisboa, 2002.

PALERMO, C. Sustentabilidade Social do Habitar. 1. ed. Florianópolis: Da autora, 2009.

PALERMO, C. Avaliação da qualidade no projeto de HIS: uma parceria com a Cohab/SC. In: VILLA, S. B.; ORNSTEIN, S. W. (Org). Qualidade Ambiental na Habitação: avaliação pós-ocupação. São Paulo: Oficina de Textos, 2013.

PEDRO, J. B. Programa Habitacional: Habitação. 4a. ed. Lisboa: Laboratórivo Nacional de Engenharia Civil, 2001. v. 1

PEDRO, J. B. Dimensões do mobiliário e do equipamento na habitação. [Lisboa: LNEC, 2011.

PEREIRA, G. M. Funcionalidade e qualidade dimensional na habitação:

Contribuição à NBR 15.575/2013. Tese (Doutorado em Arquitetura e Urbanismo), Universidade Federal de Santa Catarina, Florianópolis, 2015.

REIS, A. T. L.; LAY, M. C. D. Tipos arquitetônicos e dimensões dos espaços da habitação social. Ambiente Construído, v. 2, n. 3, p. 7-24, 2002.

SCHNEIDER, T.; TILL, J. Flexible housing. London: Architectural Press, 2007.

SILVA, E. Geometria funcional dos espaços da habitação: contribuição ao estudo da problemática da habitação de interesse social. Porto Alegre: UFRGS, 1982.

SZÜCS, C. P. et al. Sustentabilidade Social e Habitação Social. IV Encontro Nacional e II Encontro Latino-americano sobre Edificações e Comunidades Sustentáveis. Anais...Campo Grande: ANTAC, 2007.

VILLA, S. B.; CARVALHO, L. G. O. DE. Funcionalidade do Habitar Social: metodologias e soluções projetuais para uma melhor qualidade habitacional a partir da experiência do projeto [ MORA ]. XIV Encontro Nacional de

Tecnologia do Ambiente Construído. Anais...Juiz de Fora: ANTAC, UFJF, 2012.

VILLA, S. B.; GARCIA, L. C. Elementos facilitadores da qualidade no processo projetual de habitação de interesse social - A experiência metodológica do projeto MORA. V Projetar - Processos de Projetos - Teorias e Práticas. Anais...Belo Horizonte: UFMG, 2011.

VILLA, S. B.; SARAMAGO, R. C. P.; SILVA, C. AU. A. Avaliação pós-ocupação da qualidade espacial e ambiental de habitações coletivas verticalizadas destinadas a classes médias. II Congresso Internacional de Habitação Coletiva Sustentável 2015. Anais...São Paulo: FAU-USP, 2015. 